\title{
A Neo-Kleinian Approach to Comparatives
}

\author{
Jenny Doetjes, Camelia Constantinescu \& Kateřina Součková \\ Leiden University Centre for Linguistics
}

\section{Introduction}

In the literature on comparatives, one can make a rough distinction between degree-based approaches and degree-less ones. In a degree-based approach adjectives have a degree argument (Cresswell, von Stechow), or they map individuals to degrees (Kennedy). A sentence such as John is tall will mean in such an approach something like 'John is tall to a degree $d$ ', or 'John's tallness equals $d$ '. In degree-less approaches, the meaning of an adjective is that of a context sensitive or vague predicate (Klein, Larson, Van Rooij). As such, tall would correspond to 'a contextually determined set of tall individuals'.

In degree-based approaches, the comparative is usually analyzed in terms of a comparison between degrees, as in (1a) (cf. Kennedy and McNally 2005:369).
a. $\llbracket$-er/more than $d_{c} \rrbracket=\lambda A \lambda x . \exists d\left[d>d_{c} \wedge A(d)(x)\right]$
b. Alice is taller than Carmen is [AP e]
c. $\exists d\left[d>d_{c} \wedge \operatorname{tall}(d)(\right.$ Alice $\left.)\right]$

(where $d_{c}$ is the maximal degree such that Carmen is $d$-tall)

Within the vague predicate analysis degrees are not involved. Klein (1982: 127) defines the comparative in terms of a combination of conjunction and negation:
a. $\quad \mathbf{x}_{0}>_{\zeta} \mathbf{x}_{1}$ iff $\exists \mathbf{d}\left[(\mathbf{d}(\zeta))\left(\mathbf{x}_{0}\right) \wedge \neg(\mathbf{d}(\zeta))\left(\mathbf{x}_{1}\right)\right]$
(where $>_{\zeta}$ defines the comparative relation for a vague predicate $\zeta$, and d is a degree function)
b. Chris is taller than Alex is [AP e]
c. $\exists \mathbf{d}[(\mathbf{d}($ tall $))($ Chris $) \wedge \neg(\mathbf{d}($ tall $))($ Alex $)]$

In order to make this work, one has to exclude the possibility that there are two different $d$ s (degree functions) such that one of them would make Chris taller than Alex while the other would make Alex taller than Chris. This is taken care of by the Consistency Postulate in (3) (Klein 1982: 126):

$$
\begin{aligned}
& \text { Consistency Postulate }(\mathrm{CP}) \\
& \left.\left.\forall \mathbf{x}_{0} \forall \mathbf{x}_{1} \forall \mathbf{Q}\left[\exists \mathbf{d}\left[(\mathbf{d}(\mathbf{Q}))\left(\mathbf{x}_{0}\right) \wedge \neg \mathbf{d}(\mathbf{Q})\right)\left(\mathbf{x}_{1}\right)\right] \rightarrow \forall \mathbf{d}\left[(\mathbf{d}(\mathbf{Q}))\left(\mathbf{x}_{1}\right) \rightarrow \mathbf{d}(\mathbf{Q})\right)\left(\mathbf{x}_{0}\right)\right]\right] \\
& (\text { where } \mathbf{Q} \text { is a predicate variable) }
\end{aligned}
$$

We would like to thank the audiences of Scalarity in all its aspects (Ghent), TiN-dag (Utrecht) and SALT XIX. A special thanks to Jakub Dotlačil, David Nicolas and Rick Nouwen. The research for this paper has been supported by the Netherlands Organisation for Scientific Research (NWO) (grant \# 276-70-007). All usual disclaimers apply. 
In this paper we will first argue that both types of approaches have important advantages (Sections 2 and 3). In particular, the distribution of gradability across categories constitutes a strong argument in favor of a Klein type analysis, while properties of than-clauses strongly favor degree-based approaches. We will take this to be evidence in favor of a theory that combines aspects of both approaches. The proposal we will make in Section 4 involves comparison of degree functions, and makes use of the ordering relation between degree functions (when applied to an adjective) that results from the $\mathrm{CP}$ in (3). As such the proposal inherits positive properties from both the vague predicate analysis and from degree-based approaches. This will be further illustrated in Sections 5 and 6, which will deal with relative comparison (Bale's 2006, 2008 indirect comparison) and polar oppositions (Kennedy 1999a,b, 2001) respectively. Section 7 concludes the paper.

\section{Some advantages of Klein's approach}

Klein $(1980,1982)$ highlights a number of advantages of the vague predicate analysis over degree-based approaches. One of his arguments refers to pos, a null degree operator introduced by Cresswell (1976). In a degree-based system, adjectives do not start out as predicates of type $<\mathrm{e}, \mathrm{t}>$ and have to be turned into predicates at some point of the derivation. In case an overt degree operator, such as the comparative, is present, this degree operator will bind the degree variable and turn the adjective into a predicate. In the absence of a degree operator, this is taken care of by pos. Moreover, pos makes sure the adjective gets a non neutral interpretation. As shown in (4), the comparative in (4a) does not imply that John is tall. This is so because the positive in (4b) is interpreted non neutrally, as in (4c). The non neutral interpretation is attributed to the presence of pos.
a. John is taller than Peter is
$\rightarrow$
b. John is tall
c. John is taller than a contextually determined standard of tallness
d. John is [pos tall]

In Klein's framework, pos is not necessary since adjectives such as tall are interpreted as the property of being tall, where what counts as tall depends on the context. In the comparative, 'what counts as tall' is defined in such a way that John in (4a) is tall and Peter is not. Klein argues that a theory without pos has to be preferred, as proposals that make use of pos "fail to account for the fact that across a wide variety of languages the positive is formally unmarked in relation to the comparative" (Klein 1980: 2). In his view, pos is merely a device to "fix the semantics". (One could object to this that pos in (4) might be seen as a default degree operator that introduces a standard of comparison, and as such might be predicted to usually surface as a null operator cross-linguistically.)

A further issue in deciding what type of theory of gradability one would like to develop is the existence of gradable structures that are not adjectival. Even though gradability and the representation of gradability are mostly studied in the 
literature on adjectives, it was acknowledged in the literature quite early on that gradability is not an exclusively adjectival phenomenon (Sapir 1945, Bolinger 1972, Bresnan 1973). A particularly interesting case in this respect is the distribution of degree modifiers beyond the adjectival domain (see Doetjes 1997, 2008). As illustrated in (5) for Czech, certain degree modifiers that are found in the adjectival system can also be used as modifiers of gradable verbs (to love) and gradable nouns (patience) and as quantity denoting expressions if used in combination with eventive verbs (to work) and plural/mass nouns (money).
a. adjectives: hodně vysoký 'very tall'
b. nouns: hodně trpélivosti/peněz 'a lot of patience/money'
c. verbs: hodně pracovat/milovat 'to work/love a lot'

This type of distribution is not just an accidental property of Czech hodně. The examples in (6) list a number of degree modifiers in other languages that have the same kind of distribution:

$$
\begin{array}{ll}
\text { English: } & \text { little, less, enough, a bit } \\
\text { Czech: } & \text { hodně 'very, a lot', málo 'little, few', méně 'less'... } \\
\text { Italian: } & \text { molto 'very, a lot', poco 'little', più 'more'... } \\
\text { Moroccan Arabic: } & \text { bezzaf 'a lot', shwiya 'a bit' }
\end{array}
$$

The distribution of these degree modifiers can be accounted for in different ways, each of which has different consequences for the way gradability is represented across categories. Taking as a starting point the debate whether degrees are necessary in order to represent gradability, the pattern in (5) could be accounted for in three ways.

A first possibility would be to extend a degree-based analysis of gradable adjectives to the other expressions that may be modified by the degree modifiers in (6). Actually, Cresswell (1976) suggested something along these lines based on the distribution of more. Nouns such as mud and water could also be represented as gradable expressions containing a degree (or quantity) variable. Given the discussion of pos above, this type of theory should involve pos with nouns and verbs as well, as it does with adjectives. In a recent paper, Morzycki (2009) proposes in fact a nominal DegP and pos in his analysis of gradable structures such as $a$ big idiot. It is not immediately obvious whether one would like further proliferation of DegP and pos in bare plurals and mass nouns or non modified verb phrases.

A second way of looking at the data in (5) and (6) would be to assume that these modifiers are systematically ambiguous between a degree modifier and a quantifier or quantity predicate. This type of approach would be essentially the one taken by Jackendoff (1977), who argues that DegPs are only found with adjectives and that more is ambiguous between a Q (e.g. when it occurs with a noun) and a degree modifier (when used in the adjectival system). An advantage of this approach would be that it explains why certain degree modifiers such as as, too and very only modify adjectives, while others (more, less) may be used 
outside of the adjectival system. When looking at the data in more detail, it turns out to be hard to find strong arguments for this type of ambiguity other than the desire to keep degree arguments limited to the adjectival domain (see Doetjes 2008 for discussion). Other versions of an ambiguity approach, limiting degree arguments to gradable meanings, and setting apart quantity meanings, do not seem to be well motivated on the basis of the distribution of degree modifiers either.

The third option is to follow Klein $(1980,1982)$ and to assume that gradability is not a matter of degrees but a matter of the presence of an ordering. Adjectives do not contain a degree variable, pos does not exist and the interpretation of the degree modifiers can be parallel for the different categories. The key property leading to gradability is the existence of a salient ordering relation. Given current analyses of mass nouns and plurals as partially ordered sets (Link 1983) and extensions of this type of approach to the verbal domain (Krifka 1986, Bach 1986), the presence of an ordering would account for the use of expressions such as hodne in combination with nouns and verbs as well.

Even though the two first options cannot be discarded immediately, it seems clear that a degree-less analysis offers the simplest account for the distribution of degree modifiers such as hodně and for a cross-categorial representation of gradability.

\section{Than-clauses and compositionality}

One of the problematic parts of Klein's theory is the interpretation of the thanclause. In Klein's view, the information contributed by the than-clause is mapped into a structure containing a conjunction plus a negation. On the other hand, degree-based approaches treat than-clauses as objects that involve an abstraction over degrees. When looking at properties of than-clauses, there is strong evidence in favor of treating them as involving an operator variable structure, as predicted by the degree-based approaches. It is less obvious how the properties of thanclauses can be accounted for in Klein's framework.

Evidence for the claim that the semantics of the than-clauses involves an operator variable structure comes from two sources: the overt manifestation of an operator, and locality effects. Overt $w h$-operators may be present in e.g. Italian, as illustrated in (7). It is not clear what quanto would correspond to in Klein's approach (see also Izvorski 1995 for similar cases in Bulgarian).

$$
\begin{aligned}
& \text { Maria è più alta di quanto lo ero io alla sua età } \\
& \text { Maria is more tall than how (much) it was I at her age } \\
& \text { 'Mary is taller than I was at her age' }
\end{aligned}
$$

Secondly, than-clauses trigger locality effects, which has been taken as evidence that they involve an operator variable structure (see Ross 1967, Bresnan 1975, Chomsky 1977, Pinkham 1982). This is illustrated in (8), where the presence of the variable inside the complex NP island results in ungrammaticality. 
(8) a. *John is taller than [CP Op $\mathrm{x}_{\mathrm{x}}$ Peter saw [a man who is $\left.\left.\left[e_{x}\right]\right]\right]$

b. *How tall ${ }_{x}$ did Peter see [a man who is $\left.\left[e_{x}\right]\right]$

More recently, Kennedy \& Merchant (1997) attribute the absence of attributive subdeletion in sentences such as (9) to locality conditions:

*Maureen built a wider table than [CP Op $\mathrm{p}_{x}$ she did a [Degp $e_{x}$ long] desk]

The same type of locality effect is found in overt wh-questions, as illustrated by the Czech examples in (10):
a. [Jak $\quad \mathrm{moc}]_{\mathrm{i}}$ je ten abstrakt [ $e_{i}$ zajímavý]? predicative $A$ how much is that abstract interesting
b. ??[Jak moc] $]_{i}$ napsal $\left[\left[e_{i}\right.\right.$ zajímavý] abstract]? attributive $A$ how much wrote.3SG.M interesting abstract

The operator variable structure is a natural consequence of a degree-based approach: the than-clause involves abstraction over degrees. In contrast, under a Klein type approach, which involves conjunction and negation, the source of the locality effects remains at best unclear.

\section{The proposal}

Before going over to our proposal, let us look once again at Klein's original analysis:
a. Chris is taller than Alex is [AP e]
b. $\exists \mathbf{d}[(\mathbf{d}($ tall $))($ Chris $) \wedge \neg(\mathbf{d}($ tall $))($ Alex $)]$

For this to work, one has to assume that if there is a degree function $\mathbf{d}$ such that (11b) holds, there cannot be another $\mathbf{d}$ such that Alex is a member of (d(tall)), while Chris is not, as specified by the Consistency Postulate in (3).

Interestingly, as a result of (3), the degree functions are nested. As such they are ordered with respect to one another, as illustrated in Figure 1.

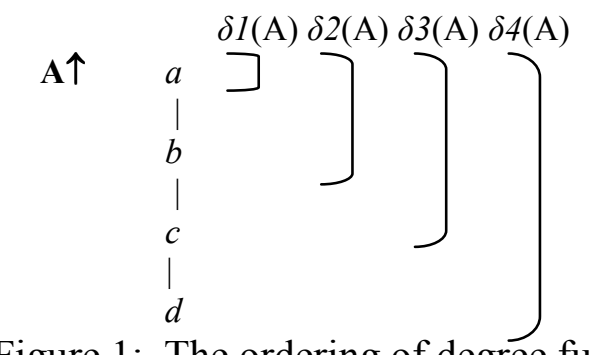

Figure 1: The ordering of degree functions

Figure 1 represents the ordered set A (a gradable adjective), which consists of the individuals $a, b, c$ and $d$. The upward arrow indicates that the highest ordered 
individual is on top and the brackets indicate which individuals are included when a given degree function applies to A. In order to avoid confusion between degrees and degree functions, we use $\delta$ for the latter.

We would like to propose that clausal comparatives involve a comparison of degree functions, rather than a comparison of degrees, and as such our proposal makes use of the ordering relation between the degree functions, as in (12).
a. Alice is taller than Carmen is
b. $\exists \delta 1\left[(\delta 1(\right.$ tall $))($ Alice $\left.) \& \delta 1<_{\text {tall }} \delta 2\right]$
( $\delta 2$ is the minimal degree function including Carmen when applied to tall and is provided by the than-clause;
$<_{A}$ expresses an ordering relation between $\delta 1$ and $\delta 2$ corresponding to 'being less inclusive/more restrictive')
c. $\delta 1<_{A} \delta 2$ iff $\delta 1(\mathrm{~A}) \subset \delta 2(\mathrm{~A})$

The than-clause defines the minimal $\delta$ that, when applied to the adjective in the main clause, results in a set including the subject of the adjective. In order for the comparative to be true, there should be a more restrictive degree function that, when applied to A, includes the subject of A. ${ }^{1}$ The immediate advantage of our modification of Klein's theory is that we now predict that than-clauses involve an operator variable structure, as they involve an abstraction over degree functions.

The next question to be addressed is how the than-clause is interpreted. We propose that there are three ways in which one can get to the minimal degree function, depending on the type of comparative involved: 1) ordinary clausal comparatives as in (13a); 2) subcomparatives involving absolute comparison as in (13b); and 3) subcomparatives with a relative interpretation as in (13c). The differences between the last two types, both of which can be distinguished from the first type because they involve an overt adjective in the than-clause, will be discussed in detail below.
a. Alice is taller than Carmen is
b. The desk is longer than the table is wide
c. Ben is funnier than Steve is rich

In ordinary clausal comparatives, the than-clause is interpreted as the minimal $\delta$ such that $x$ is $\delta(A)$, where the value of $\mathrm{A}$ is provided by the main clause. The ordering between the different $\delta$ is introduced by the ordering on $\mathrm{A}$, and as a

\footnotetext{
${ }^{1}$ The most restrictive degree function corresponds to the highest degree in a degree-based approach and the minimal degree function corresponds to the maximal degree (cf. Von Stechow 1984). As a result the ordering relation between the degree functions is reversed as compared to the ordering relation between degrees. Alternatively, one could keep the original ordering by selecting the 'maximally informative' rather than the 'maximally restrictive' or minimal degree function, $\delta 1$ being the 'maximally informative' degree function in Figure 1 (cf. Beck \& Rullmann 1999). Note that, in view of the existence of modifiers such as less, one probably needs two MIN/MAX operators, one for the main clause and one for the than-clause (see Von Stechow 1984). For reasons of simplicity we will omit the main clause operator, as its presence is not relevant for any of the examples discussed in this paper.
} 
result this is only possible in cases where there is only one adjective that determines the relative ordering of the individuals that are compared. In (14), the meaning of the comparative and of the than-clause are given for the sentence in (13a) (cf. Kennedy 1999:131-150 for a similar treatment of the interpretation of the adjective in the than-clause and arguments in favor of such an approach):

$$
\begin{array}{ll}
\text { a. } & \| \text { more }- \text { er } \|=\lambda A \lambda Q \lambda x . \exists \delta\left[(\delta(A))(x) \& \delta<_{A} Q(A)\right] \\
\text { b. } & \| \text { than Carmen is } \|=\lambda A\left(\operatorname{MIN}_{\mathrm{A}}(\lambda \delta(\delta(A))(\text { Carmen }))\right) \\
\text { c. } & \| \text { taller than Carmen is } \|= \\
& \lambda Q \lambda x . \exists \delta 1\left[(\delta 1(\text { tall }))(x) \& \delta 1<_{\text {tal }} Q(\text { tall })\right](\lambda A(\operatorname{MIN}(\lambda \delta 2(\delta 2(A))(\mathrm{C})))) \\
& \lambda x . \exists \delta 1\left[(\delta 1(\text { tall }))(x) \& \delta 1<_{\text {tall }} \lambda A\left(\operatorname{MIN}_{A}(\lambda \delta 2(\delta 2(A))(\mathrm{C}))\right)(\text { tall })\right] \\
& \lambda x . \exists \delta 1\left[(\delta 1(\text { tall }))(x) \& \delta 1<_{\text {tall }} \operatorname{MIN}_{\text {tall }}(\lambda \delta 2(\delta 2(\text { tall }))(\mathrm{C}))\right]
\end{array}
$$

(14) can be illustrated with respect to Figure 1 above. If we assume Alice is $a$ and Carmen is $c$, then the minimal degree function that, when applied to tall includes Carmen is $\delta 3$, and given that there is a more restrictive degree function that, when applied to tall includes Alice ( $\delta 1$ or $\delta 2)$, the sentence comes out as true.

As we already indicated, subcomparatives involve two different adjectives: one in the main clause and one in the than-clause. The two adjectives involve different orderings, and as such, the definition of the degree function provided by the thanclause in terms of either adjective will not do. This can be illustrated on the basis of (13b). If we define the minimal degree function on the basis of the adjective given by the main clause, the sentence would obtain the wrong meaning: it would mean that the desk is longer than the table. On the other hand, if we define the degree function on the basis of the adjective in the than-clause, it is not ordered with respect to the degree functions applying to the adjective in the main clause. The only way to avoid this type of problem is to make use of degree functions that are intrinsically ordered, so that the different orderings presented by the adjectives will not affect the relative order of the degree functions when applied to the different adjectives.

For cases such as (13b), we assume that the grammar makes use of degree functions based on measures. Following Klein (1982: 120-1), we assume that a measure in expressions such as five foot six tall is interpreted as a function $h$ that partitions the domain into those individuals that measure at least five foot six and those that do not. Measure based degree functions (e.g. two meters, six feet) are always ordered in the same way, irrespective of the set they combine with. This is so because their ordering is fixed by the independent ordering of the measures they are based on. Given that measures only combine with dimensional adjectives, this only works for cases where the comparative contains two dimensional adjectives that make use of the same type of measurement (we will come back to this issue in more detail in Section 6 below). The sentence in (13b) can be analyzed as in (15). The than-clause provides the minimal measure based $\delta$ such that the table is $\delta$ (wide), and this measure can also be applied to the adjective in the main clause. The analysis results in absolute comparison, that is, comparison of the measure that defines the width of the table and the one defining the length of the desk. 
a. $\|$ more/-er $\|=\lambda A \lambda \delta 2 \lambda x . \exists \delta 1\left[(\delta 1(A))(x) \& \delta 1<_{A} \delta 2\right]$

b. $\|$ than the table is wide $\|=\operatorname{MIN}_{\text {wide }}(\lambda \delta(\delta($ wide $))($ table $))=$ measure

c. \|longer than the table is wide $\|=$

$$
\begin{aligned}
& \lambda A \lambda \delta 2 \lambda x . \exists \delta 1\left[(\delta 1(A))(x) \& \delta 1<_{A} \delta 2\right](\text { long }) \\
& \lambda \delta 2 \lambda x . \exists \delta 1\left[(\delta 1(\text { long }))(x) \& \delta 1<_{\text {long }} \delta 2\right]\left(\operatorname{MIN}_{\text {wide }}(\lambda \delta(\delta(\text { wide }))(\text { table }))\right) \\
& \lambda x . \exists \delta 1\left[(\delta 1(\text { long }))(x) \& \delta 1<_{\text {long }} \operatorname{MIN}_{\text {wide }}(\lambda \delta 2(\delta 2(\text { wide }))(\text { table }))\right]
\end{aligned}
$$

In addition to subcomparatives like the one in (13b), there is a different type of subcomparative in which two adjectives are compared that do not correspond to a single scale or dimension (see Bale 2006, 2008). Given that these structures involve evaluative rather than dimensional adjectives (in the sense of Bierwisch 1989), they are incompatible with measure based degree functions. We propose that in this case degree functions corresponding to expressions such as quite, very and extremely are involved (cf. McConnell-Ginet 1973). On a par with measures, these expressions can be interpreted with respect to different adjectives and they can be intrinsically ordered with respect to one another: the ordering of these expressions is independent of the adjective to which they are applied (quite $>$ very $>$ extremely, that is, e.g. extremely results in a more restrictive set than very etc.). The analysis of (13c) is given in (16). We will refer to this type of sentences as cases of relative comparison as opposed to the case of absolute comparison in (15).
a. $\quad \|$ morel-er $\|=\lambda A \lambda \delta 2 \lambda x . \exists \delta 1\left[(\delta 1(A))(x) \& \delta 1<_{A} \delta 2\right]$
b. $\|$ than Steve is rich $\|=\operatorname{MIN}_{\text {rich }}(\lambda \delta(\delta($ rich $))($ Steve $))=\mathrm{a} \delta$ such as very
c. e.g. if Steve is very rich, Ben has to be extremely funny

The two last types will be discussed in more detail in the next two sections. We will start out with relative comparison, as this type is predicted to be ruled out in degree-based approaches as cases of incommensurability, since degrees corresponding to different dimensions should not be comparable (cf. Kennedy 1999 for discussion). As such, the existence of relative comparison can be seen as an important reason to adopt a Klein-style analysis.

\section{Relative comparison}

Relative comparison is discussed at length by Bale (2006, 2008). Some of his examples are given in (17):

(17) a. If Esme chooses to marry funny but poor Ben over rich but boring Steve, then there can be only one explanation. Ben must be funnier than Steve is rich.

b. Although Seymour was both happy and angry, he was still happier than he was angry.

c. Seymour is as intelligent as Esme is beautiful 
As Bale points out, these examples cannot be accounted for under a standard degree-based approach, as they involve incommensurable degrees. Bale argues that the existence of this type of sentences is evidence in favor of mapping of degrees onto a universal scale, which makes comparison of incommensurable degrees possible (see also Bartsch \& Vennemann 1972: 92 who briefly discuss the phenomenon and sketch a similar proposal). ${ }^{2}$ In fact, it seems that this is the only way to account for this type of sentences within a degree-based approach. The analysis proposed above can account for these data without the assumption of a mapping to a universal scale: the only thing one has to adopt is that degree expressions such as very and extremely may be used as degree functions when interpreting this type of sentences.

Even though relative comparisons sound odd when used out of the blue, in the right context they become perfect. The following examples in Dutch, all of which are attested examples, illustrate this point.

a. Gelukkig was het eten even smakelijk als het zwaar was (internet) 'Luckily the meal was as tasty as it was heavy'

b. Daarna werd Finn even wijs als hij krachtig en dapper was (internet) 'After that, Finn became as wise as he was strong and courageous'

c. "Als de graaf een schelm en een schurk is, zou hij het Geschrift nooit aan zijn neef gegeven hebben!" zei Frans. "Of hij moet nog dommer zijn dan hij schurkachtig is." ～(Tonke Dragt, De zevensprong) "If the count is a scoundrel and a villain [as you were saying], he would never give the Manuscript to his nephew!" said Frans. "Or he has to be even more stupid than he is villainous."

The context dependency is nicely illustrated by the example in (18c). The previous context describes the count as a very villainous person. This makes sure that the reader knows how to interpret the sentence (the count has to be extremely stupid). Moreover, the context provides a reason to use a comparison between the two properties corresponding to the two adjectives: if the count were villainous, it would have been stupid of him to give the manuscript to his nephew.

Bale points out that relative comparisons do not necessarily imply that the properties expressed by the adjectives hold of the subjects (i.e. there is no entailment to the positive form), even though this sentence type is often used to convey a high degree interpretation as in (18c). An attested Dutch example that clearly illustrates this point is given in (19):

(19) Gelukkig was [de hond] veel slimmer dan hij mooi was, dus konden we ook van alles met hem doen op het gebied van gedragstraining (internet) 'Luckily the dog was much smarter than he was good-looking, so we could do all sorts of things with him in the domain of behavior training'

\footnotetext{
${ }^{2}$ Bale uses the term indirect comparison to refer to sentences such as the ones in (17), which is meant to reflect his analysis in terms of a comparison mediated by a mapping onto the Universal Scale. We use the theory neutral term 'relative comparison'.
} 
According to Bale (2006), relative comparisons that compare values near the extremities are more natural. In the (2008) paper, he argues that this preference is due to the fact that these sentences introduce prototypical characters and the properties these characters are famous for (e.g. Einstein/intelligence, Medusa/ugliness). Thus he argues that the effect should be attributed to the fact that people tend to be famous for having a particular property to a large rather than an average extent. We think this conclusion is not right. Going back to (19), two things must be considered. In the first place, the sentence does not only suggest that the dog is not really good-looking, it strongly suggests that the dog is ugly. In the second place, if one wants to change the example in such a way that the negative adjective lelijk 'ugly' is used rather than the positive adjective mooi 'good-looking', an interpretation similar to the one in (19) is not available. This particular example is not unique in this respect. All the relevant examples discussed by Bale involve a positive adjective in the than-clause, and it seems quite impossible to come up with a good example involving a negative adjective. Both properties can be understood under the assumption that the use of mooi is ironical in this case, and involves a criticism under the guise of praise (cf. Leech 1969). This accounts for the fact that the sentence is not merely neutral but rather indicates that the dog is quite ugly. The asymmetry between positive and negative adjectives also follows from the ironical use of the adjective in the than-clause (see also Sperber \& Wilson 1981, who observe that positive terms are generally more likely to be used ironically). Within our analysis, the ironical use of the adjective mooi has the effect of stretching up the domain of mooi as to include even the ugly dog. We think this triggers a similar extension of the domain of slim 'smart'. This is an interesting phenomenon that deserves further research.

In our analysis, the absence of a truly neutral interpretation correlates with the fact that the degree functions involved in this reading (quite, very, extremely) generally exclude a neutral interpretation.

It is important to realize that relative comparison cannot be analyzed in terms of metalinguistic comparison (see also Bale 2008). Metalinguistic comparison, as in (20), differs from cases such as the ones in (17)-(19) in various ways. For reasons of space we just mention the fact that metalinguistic comparison always involves the use of the analytic comparative (more in English and meer in Dutch) while in the examples above the synthetic comparative is used.

The cases in (17)-(19) cannot be analyzed as cases of comparison of deviation either (COD, Kennedy 1999, 2001). In fact, we will argue below that COD should be seen as a special case of relative comparison. In order to see why, let us have a look at a case of comparison of deviation in (20):

(20) San Francisco Bay is more shallow than Monterey Bay is deep (\# but Monterey Bay is not deep)

According to Kennedy $(1999,2001)$, COD has three crucial properties that distinguish it from other comparative structures. First, it involves comparison of differential extents corresponding to the difference between the actual degree and the standard. As a result, the meaning of the adjective in the positive is 
presupposed. This is why adding but Monterey bay is not deep in (20) is odd. Second, even with adjectives that normally take a synthetic comparative, the analytic comparative is used. This is illustrated by the example in (20), where more shallow is used rather than shallower. Third, COD applies to adjectives that involve comparable or commensurable dimensions.

According to Kennedy COD is derived by mapping the two differential extents $\left(e_{1}\right.$ and $\left.e_{2}\right)$ onto two extents that both begin at the zero point of the same scale $\left(e^{\prime}{ }_{1}\right.$ and $e_{2}^{\prime}$ in (21b)) (Kennedy 1999: 211-212). This derives the third property of COD mentioned above. Kennedy (2001) obtains this mapping by the ZERO function as in (21c).

a. William is as tall as Robert is short

b. HEIGHT:

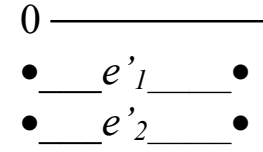

c. $\operatorname{ZERO}\left(\right.$ tall $($ William $\left.)-d_{\text {s.tallness }}\right) \geqslant \operatorname{ZERO}\left(\right.$ short $($ Robert $\left.)-d_{\text {s.shortness }}\right)$

This analysis predicts that the adjectives in COD structures must involve degrees on a single scale. This is the case of antonyms as in (20) and in (21a), and 'commensurable' dimensional adjectives such as long and wide, which for the same reason can also occur in absolute comparisons (see Kennedy 1999: 51 for discussion). The latter case is illustrated in (22) (Kennedy 2001: 43). The reading in (22b) corresponds to the absolute comparison reading of the sentence (which is false), and (22c) to the comparison of deviation reading (which is arguably true).

(22) a. The Sears Tower is as tall as the San Francisco Bay Bridge is long.

b. The height of the Sears Tower is at least as great as the length of the San Francisco Bay Bridge.

c. The degree to which the Sears Tower exceeds a standard of tallness (for buildings) is at least as great as the degree to which the San Francisco Bay Bridge exceeds a standard of length (for bridges).

Given the properties of COD discussed above, it is clear that the cases in (17)-(19) cannot be analyzed in terms of comparison of deviation: the adjectives correspond to different scales (see also Bale 2006, 2008). Note, on the other hand, that the meaning we get for these sentences is very similar, especially if we set aside the effect created by irony in (19).

The use of the analytic comparative in COD might well be related to the type of interpretation these sentences get. It has been observed by Rett (2008a:109) that more, when found in parallel distribution with the synthetic comparative -er, tends to have an evaluative or non neutral interpretation, which results in a presupposition similar to the one we find in (20):
a. Adam is taller than Doug
$\rightarrow \quad$ Doug is tall
b. Adam is more tall than Doug
$\rightarrow \quad$ Doug is tall 
The oddness of the continuation in (20) may be due to the non neutral interpretation that (at least) some speakers have for more when it is in parallel distribution with $-e r$, as illustrated in (23). The use of non neutral or evaluative more in comparison of deviation cases may facilitate an interpretation that is not so readily available and is strongly context dependent. The use of more rather than -er is thus comparable to the use of nog 'even' in the relative comparative in (18c), which also improves the sentence in the given context. Note also that examples of COD with the synthetic comparative can actually be found.

Bierwisch (1989:105) discusses COD with a synthetic comparative in German:

?Hans is kleiner als Eva groß ist

'Hans is shorter than Eva is tall'

The meaning of the sentence is described in terms of COD. The effect obtained in (19) above, in which the second adjective is not presupposed, is hard to get with two antonymous adjectives. Assume the ironical reading of (19) applied to (24). Eva would be short rather than tall, and at the same time Hans would not need to be very short and in fact might even be taller than Eva. Given the fact that the two adjectives define opposite directions on the same scale (or opposite orderings of the same set of individuals) the ironic reading is highly confusing and may simply be impossible to process.

So far there do not seem to be convincing reasons to assume that COD and relative comparison constitute separate phenomena. In the remainder of this section we will argue that there is actually some evidence in favor of extending the relative comparison analysis to what have been argued to be cases of COD. According to the standard analysis of COD, two differential extents have to be compared to one another after they have been mapped onto the same scale. This involves absolute comparison in the sense that the absolute values of the extents on the scale are compared. An analysis in terms of relative comparison predicts that the comparison is relative to the standard: whether something is very $A$ or extremely $A$ will be determined with respect to a comparison class. The two theories do not make very different predictions in cases where the adjectives have similar standards. However, in those cases where the standards are clearly of a different order, the two theories do make clearly different predictions: the COD analysis predicts absolute comparison of the extents above the standard, and a relative comparison analysis predicts that the comparison is not absolute because the evaluation takes into account two different comparison classes.

In order to see how this works, consider again the reading $(22 \mathrm{c})$ of the sentence in (22a) above. This example is suitable to test the predictions of the two approaches, as the comparison classes for (long) bridges and (high) towers will not yield a comparable standard. Let us start with the actual value of the height of Sears Tower and the length of San Francisco Bay Bridge. The former measures $527 \mathrm{~m}(1,730 \mathrm{ft})$, including the antenna, while the latter has a total length of 5,920 $\mathrm{m}$ (3.68 miles). Let us now assume that the standard of tallness for buildings is $100 \mathrm{~m}$ and the standard of length for bridges $5,500 \mathrm{~m}$. This would give us two similar differential extents: $427 \mathrm{~m}(527 \mathrm{~m}-100 \mathrm{~m})$ for the tallness of Sears 
Tower, and $420 \mathrm{~m}(5,920 \mathrm{~m}-5,500 \mathrm{~m})$ for the length of the bridge. As such we would expect the sentence to be true under a COD interpretation. However, in this scenario the bridge is hardly longer than the standard (for bridges), while the tower is way higher than the standard (for towers), and we have the intuition that the sentence would be false. If we assume again that the standard of tallness for buildings is $100 \mathrm{~m}$, but now the standard of length for bridges is $1,000 \mathrm{~m}$, the absolute length of the differential extents would be very different $(427 \mathrm{~m}$ for the building vs. $4,920 \mathrm{~m}$ for the bridge). However, we do have the feeling that this is a more appropriate scenario to make the sentence come out as true. This suggests that the sentence has a relative comparison interpretation, as the deviations are similar to one another only when taking into account the difference between the two standards. Whenever the standards are clearly different, this effect can be found. Note also that if people are willing to accept the sentence in (22a), they do not need to have a clear idea of what the standard is nor about the exact tallness or length of the bridge. Rather, they have the feeling that one can classify Sears Towers among the very tall buildings and San Francisco Bay Bridge among the very long bridges.

In this section we have argued that relative comparison provides a way of comparing 'incommensurable' adjectives. Moreover, we argued that COD has to be seen as a subcase of relative comparison.

\section{Absolute comparison}

In this section we turn to subcomparatives that involve absolute comparison. As stated above, we assume that this reading involves measure based degree functions. As Kennedy argues, absolute comparison is not possible if the adjective in the main clause and the adjective in the than-clause are polar opposites. If the two adjectives have the same polarity, no problem arises. This is illustrated for POS-POS (positive adjective in both the main clause and the than-clause) and for POS-NEG (negative adjective in the than-clause) in (25):
a. The desk was longer than the table was wide $\mathrm{OK}$
POS-POS

b. ?Alice is taller than Carmen is short

ANOMALY POS-NEG

Kennedy takes this to be evidence in favor of a degree-based approach that makes use of positive and negative degrees. As these degrees are sortally different they create an effect of incommensurability.

However, the data are more complicated in two respects. In the first place, as discussed by Büring (2008), there also exist cross-polar nomalies. In the second place, comparatives with two negative adjectives are not as good as the ones with two positive adjectives as in (25a). Cross-polar nomalies, as Büring calls them, are of the NEG-POS type. Büring claims that a negative adjective $A^{\text {neg }}$ is reanalyzed as little plus the positive counterpart of the adjective $\mathrm{A}^{\mathrm{pos}}$. As a result, shorter in (26a) corresponds to less long. The example in (26b) contains two antonyms and 
is degraded. According to Büring, the sentence in (26b) is out because of the obligatory nature of comparative deletion as also illustrated in (26c).

a. Unfortunately, the ladder was shorter than the house was high

b. ?*Unfortunately, the hose is shorter than the ladder is long

c. ?*Unfortunately, the hose is less long than the ladder is long

The existence of NEG-POS structures is also noted and discussed by Bierwisch (1989:105), who gives the following paradigm for German (Bierwisch 1989: 105):

a. Der Tisch ist höher als er breit ist

POS-POS the table is higher than it wide is

b. ?Der Tisch ist niedriger als er breit ist NEG-POS the table is lower than it wide is

c. ?Der Tisch ist niedriger als er schmal ist

NEG-NEG the table is lower than it narrow is

d. ??Der Tisch ist höher als er schmal ist POS-NEG the table is higher than it narrow is

According to Bierwisch, (27b) is slightly degraded because of the combination of a positive and a negative adjective. The sentences in $(27 \mathrm{c}, \mathrm{d})$ (with a negative adjective in the than-clause) need to have an absolute comparison reading. As a result of this, it is not possible to add a differential phrase such as $10 \mathrm{~cm}$. These sentences are acceptable under a relative comparison interpretation only.

In this respect, the judgments in Bierwisch differ from the ones in Kennedy, who claims that there is a contrast between the examples in (28):

a. Luckily, the ficus turned out to be shorter than the doorway was low

NEG-NEG

b. \#Unfortunately, the ficus turned out to be taller than the ceiling was low POS-NEG

The variation in judgments found in the literature reflects a variation among the speakers (both native Dutch and native English) that we consulted. Their judgments seem to form a continuum: (comparatives with one A $>$ ) POS-POS $>$ NEG-POS $>$ NEG-NEG $>$ POS-NEG.

Our internet searches show the same patterns as the judgments in Bierwisch. POS-POS cases are rather frequent; NEG-POS cases are less frequent but can be found rather easily, provided a proper context (e.g. descriptions of the body of an insect, where length and width are not defined with respect to each other but with respect to the head and the tail). Sentences with negative adjectives in the thanclause are extremely rare, and most of those that can be found clearly have a relative comparison interpretation. We found two English examples of sentences with negative adjectives in the than-clause and both were of the POS-NEG, which is rather surprising given the preferences of informants for the NEG-NEG type. In all examples, the use of a negative adjective in the than-clause triggers a non 
neutral reading for this adjective, while the use of a negative adjective in the main clause does not, as has been observed in the literature.

It seems clear that any theory that wants to account for the data has to say something about the special behavior of negative adjectives. Also, given the variation that is found, it seems reasonable to develop a theory that does not exclude certain possibilities in an absolute way, but rather one that accounts for the various degrees of acceptability that can be found.

We would like to suggest that the core of the problem of negative adjectives lies in the nature of measure based degree functions, which, as suggested by Klein, have an at least-interpretation. The Consistency Postulate in (3) excludes the at least-interpretation in combination with negative adjectives, as this would result in the wrong type of nesting, as illustrated in Figure 2 (bold brackets). Instead, the measures should have an at most-interpretation, as indicated by the dotted brackets. $^{3}$

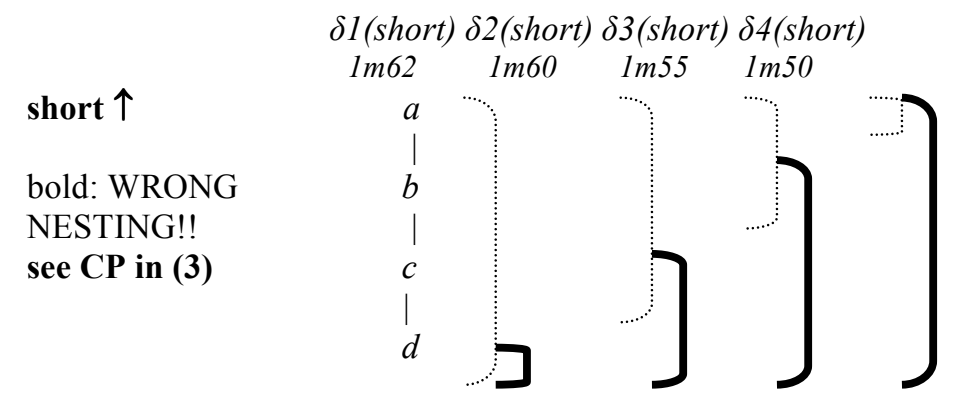

Figure 2: Negative adjectives and the interpretation of measure based degree functions

This means that, in accordance with the $\mathrm{CP}$, the measure based degree functions should have an at least-type interpretation with positive adjectives and an at mosttype interpretation with negative adjectives. We assume that the at leastinterpretation is basic, while the at most-interpretation is obtained by coercion and only obtains with negative adjectives. As such, we expect all absolute comparison cases that contain a negative adjective to be degraded as compared to the POS-POS cases. Note that this does not hold for ordinary comparatives with a negative adjective, as in that case measure based degree functions do not play a role.

The next question is how to account for the difference between NEG-POS (positive adjective in the than-clause) and POS/NEG-NEG (negative adjective in the than-clause). One can observe that the difference in acceptability between the two types of sentences correlates with two other differences. In the first place, only a negative adjective in the than-clause introduces the presupposition that it holds of its subject, as illustrated in (29a) vs. (29b). ${ }^{4}$

\footnotetext{
${ }^{3}$ Similarly, measures are found with positive rather than negative adjectives. While $1 \mathrm{~m} 70$ tall is fine, $1 \mathrm{~m} 50$ short is not. If it is used, it is stylistically marked and presupposes shortness.

${ }^{4}(29 a)$ is one of the two clear examples of absolute comparison with a negative adjective in the than-clause that we have found on the internet. Most cases of subcomparatives with a positive adjective in the main clause and a negative adjective in the than-clause that we found were clear cases of relative comparison. In this particular example, the sentence was followed by a precise specification of the measures: It's something like $1000 \mathrm{ft}$ wide at the top and $1700 \mathrm{ft}$ deep. This
} 
a. This is a part of the canyon where it is deeper than it is narrow $\rightarrow$ the canyon is narrow

b. Unfortunately, the ladder was shorter than the house was high (=26a) $\rightarrow$ the ladder was short

In the second place, only a negative adjective in the than-clause may be replaced by its positive counterpart without changing the truth conditions of the sentence:

(30) a. The canyon is deeper than it is narrow/wide

b. The ladder was shorter/longer than the house was high

We assume that the presupposition in the than-clause is triggered by the fact that there has to be a reason for using a negative adjective rather than the corresponding positive adjective. In (30b) the negative adjective cannot be replaced by its positive counterpart without affecting the truth conditions of the sentence, and as such there is a clear reason to use the negative adjective. In (30a), the negative adjective may be replaced by its positive counterpart, and the presupposition is triggered. The effect is similar to the one described by Rett (2008b) who discusses the contrast between as tall and as short. According to Rett, both forms have a non neutral and a neutral reading. However, under their neutral readings the two forms have the same meaning, and as a result the one with the more marked negative adjective is blocked. As a result, as short only has a non neutral (or evaluative) reading.

The question that remains is why negative adjectives are so difficult in thanclauses, and why they are used more easily in main clauses (29b) and with equatives (as short). If one wants to assume that the negative adjectives in the main clause trigger coercion, one has to assume that the at most-interpretation with negative adjectives is quite easily obtained, since cross-polar nomalies such as (29b) are more acceptable and more frequent than cases with a negative adjective in the than-clause. This means that the difficulty lies in the combination of the measure and the non neutral interpretation of the adjective. It might be the case, for instance, that unlike equatives, measures do not easily combine with non neutral interpretations of an adjective, be it positive or negative. This might be on the right track, given that \#1m50 short is clearly less acceptable than as short. More research is necessary on the nature of neutral and non neutral readings in order to see whether this view can be maintained.

\section{Conclusions}

In this paper we developed an alternative to Klein's theory of comparatives. Klein does not need degrees in the ontology and by that his theory is better suited to deal with cross-categorial degree modification. Unlike Klein's original approach,

strongly suggests that the sentence is intended to have an absolute comparison interpretation. The narrowness of the canyon is contextually salient, as the text describes a canyon on a picture entitled narrow canyon. 
our alternative captures the semantic contribution and structure of the than-clause. As we have shown, it can account for certain other phenomena at least as well as degree-based approaches (relative comparisons are analyzed without assuming a mapping to a universal scale and the different patterns of subcomparatives with absolute interpretations can be accounted for). Obviously, various issues still need to be worked out, such as the use of quantifiers in than-clauses (see Larson 1988, Schwarzschild \& Wilkinson 2002, Van Rooij 2008) and the distribution of differential and factor phrases (see Schwarzschild 2005). However, given the advantages discussed above, we do think that our proposal is a serious alternative to degree-based approaches.

\section{References}

Bach, Emmon: 1986, 'The algebra of Events', Linguistics \& Philosophy 9, 5-16.

Bartsch, Renate \& Theo Vennemann: 1972, Semantic Structures, Athenäum, Frankfurt.

Bale, Alan: 2006, The universal scale \& the semantics of comparison. Dissertation, McGill University.

Bale, Alan: 2008, 'A universal scale of comparison', Linguistics \& Philosophy 31(1), 1-55.

Beck, Sigrid \& Hotze Rullmann: 1999, 'A flexible approach to exhaustivity in questions', Natural Language Semantics 7(3), 249-297.

Bierwisch, Manfred: 1989, 'The semantics of gradation', in M. Bierwisch \& E. Lang (eds.), Dimensional Adjectives, Springer-Verlag, Berlin. 71-262.

Bresnan, Joan: 1973, 'Syntax of the comparative clause construction in English', Linguistic Inquiry 4(3), 275-343.

Bresnan Joan: 1975, 'Comparative deletion and constraints on transformations', Linguistic Analysis 1, 25-74

Bolinger, Dwight: 1972, Degree words, Mouton, The Hague.

Büring, Daniel: 2008, 'Cross-polar nomalies', in M. Gibson \& T. Friedman (eds.), Proceedings of SALT XVII, CLC Publications.

Chomsky, Noam: 1977, 'On wh-movement', in P. Culicover, T. Wasow \& A. Akmajian (eds.), Formal Syntax, Academic Press, New York, 71-133.

Cresswell, Max J.: 1976, 'The semantics of degree', in Partee, B. (ed.), Montague grammar, Academic Press, New York, 261-292.

Doetjes, Jenny: 1997, Quantifiers and selection. On the distribution of quantifiers in French, Dutch and English. Dissertation, Leiden University.

Doetjes, Jenny: 2008, 'Adjectives and degree modification', in L. McNally \& C. Kennedy (eds.), Adjectives and Adverbs: Syntax, Semantics and Discourse, Oxford University Press, $123-155$.

Izvorski, Roumyana: 1995, 'A solution to the subcomparative paradox', in J. Camacho, L. Choueri \& M. Watanabe (eds.), The Proceedings of WCCFL 14, CSLI Publications, Stanford, 203-219.

Jackendoff, Ray: 1977. X-bar Syntax, MIT Press, Cambridge.

Kennedy, Christopher: 1999, Projecting the adjective. The syntax and semantics of gradability and comparison, Garland, New York and London. 
Kennedy, Christopher: 2001, 'Polar opposition and the ontology of 'degrees', Linguistics \& Philosophy 24, 33-70.

Kennedy, Christopher \& Louise McNally: 2005, 'Scale structure, degree modification and the semantic typology of gradable predicates', Language 81, 345-381

Kennedy, Christopher \& Jason Merchant: 1997, 'Attributive comparatives and bound ellipsis', Linguistics Research Center report LRC-97-03, University of California, Santa Cruz.

Klein, Ewan: 1980, 'A semantics for positive and comparative adjectives', Linguistics \& Philosophy 4(1): 1-46.

Klein, Ewan: 1982, The interpretation of adjectival comparatives. Journal of Linguistics 18, 113-136.

Krifka, Manfred: 1986. Nominalreferenz und Zeitkonstitution. Zur Semantik von Massentermen, Pluraltermen und Aspektklassen. Dissertation, LudwigMaximilians-Universität München.

Larson, Richard: 1988, 'Scope and comparatives', Linguistics \& Philosophy 11, $1-26$.

Leech, Gregory: 1969, A linguistic guide to English poetry, Longman, London.

Link, Godehard: 1983, 'The logical analysis of plurals and mass terms' in R. Bäuerle, C. Schwarze \& A. von Stechow (eds), Meaning, use and interpretation of language. Walter de Gruyter, Berlin, 302-323.

McConnell-Ginet, Sally: 1973, Comparative constructions in English. Dissertation, University of Rochester.

Morzycki, Marcin: 2009, 'Degree Modification of Gradable Nouns: Size Adjectives and Adnominal Degree Morphemes', Natural Language Semantics 17(2), 175-203.

Pinkham, Jessie: 1982, The formation of comparative clauses in French and English. Dissertation, Indiana University

Rett, Jessica: 2008a, Degree modification in natural language. Dissertation, Rutgers University

Rett, Jessica: 2008b, 'Antonymy and evaluativity', in M. Gibson \& T. Friedman (eds.), Proceedings of SALT XVII, CLC Publications.

Ross, John R.: 1967, Constraints on variables in syntax. Dissertation, MIT.

Rooij, Robert van: 2008, 'Comparatives and quantifiers', in O. Bonami \& P. Cabredo-Hofherr (eds.), Empirical Issues in Syntax and Semantics 7, 1-22.

Sapir, Edward: 1945, 'Grading: A study in Semantics', Philosophy of Science 11, 93-116.

Schwarzschild, Roger: 2005, 'Measure phrases as modifiers of adjectives', Recherches Linguistiques de Vincennes 35, 207-228.

Schwarzschild, Roger \& Karina Wilkinson: 2002, 'Quantifiers and comparatives', Natural Language Semantics 10, 1-41.

Sperber, D. \& D. Wilson: 1981, 'Irony and the use-mention distinction', in P. Cole (ed.). RadicalPragmatics, Academic Press, New York, 295-318.

von Stechow, Arnim: 1984, 'Comparing semantic theories of comparison', Journal of Semantics 3, 1-77. 